\title{
Biaxial surface potential effects in polymer-stabilized ferroelectric liquid crystal cells
}

\author{
W.Q. Song ${ }^{1}$, A. A. Kudreyko ${ }^{2, \dagger}$, N. G. Migranov ${ }^{2}$ \\ †akudreyko@bashgmu.ru \\ ${ }^{1}$ School of Electronic and Electrical Engineering, Shanghai University of Engineering Sciences, 333 Long Teng Road, \\ Shanghai, 201620, China \\ ${ }^{2}$ Bashkir State Medical University, 3 Lenina St., Ufa, 450008, Russia
}

The interplay between volume and surface effects in polymer-stabilized ferroelectric liquid crystals often results in the so-called "quasi-bookshelf" or tilted layer structure. Universal description of director (the most probable orientation of long molecular axes and the optical axis) distribution within ferroelectric liquid crystal cell, stabilized by polymer network implies consideration of the confined volume effects. The discussed model of polymer-stabilized ferroelectric liquid crystal cell was investigated in terms of the continuum elastic theory with anisotropic surface effects, which also account the most probable orientation of short molecular axes. Promising applications of the biaxial surface potential for fabrication of electro-optic cells with the desired surface parameters have motivated us to embark upon the proposed model. Our model also accounts splay deformation of the spontaneous polarization. This enables us to calculate the applied voltage by the electric field and vice versa. The effect of polymer stabilization on the director orientation profiles across the cell was examined. We have found that the director-polymer network interaction coefficient yields insignificant difference between the director orientation profiles in the smectic $\mathrm{C}^{\star}\left(\mathrm{SmC}^{\star}\right)$ phase of ferroelectric liquid crystal. We believe that this theoretical model can be useful for fabrication of experimental cells because the issues, which follow from the biaxial surface potential allow to control bi- and monostability of surface-stabilized ferroelectric liquid crystal cells, domain structures in electro-optical cells and the planar alignment quality.

Keywords: thin films, polymer-stabilized ferroelectric liquid crystals, Euler's equation.

УДК: 532.783

\section{Эффекты двуосного поверхностного потенциала в ячейках сегнетоэлектрических жидких кристаллов, стабилизированных полимерными сетками}

\author{
Сонг В. ${ }^{1}$, Кудрейко А. А. ${ }^{2, \dagger}$, Мигранов Н. Г. ${ }^{2}$ \\ ${ }^{1}$ Шанхайский инженерно-технический университет, Лонг Тенг Роуд , 333, Шанхай, 201620, Китай \\ ${ }^{2}$ Башкирский государственный медицинский университет, ул. Ленина, 3, Уфа, 450008, Россия
}

Взаимосвязь объёмных и поверхностных эффектов в сегнетоэлектрических жидких кристаллах, стабилизированных полимерными сетками зачастую приводит структуры смектических слоёв к наклонному ориентационному порядку. Решение задачи распределения директора (наиболее вероятного направления длинных молекулярных осей, которое также является главной оптической осью) в сегнетоэлектрической жидкокристаллической ячейке, стабилизированной полимерными сетками, предполагает изучение эффектов ограниченного объёма. Рассматриваемая в данной работе модель ячейки сегнетоэлектрического жидкого кристалла, стабилизированного полимерными сетками, изучена в рамках континуальной теории упругости с учётом проявления двуосности молекул на анизотропных подложках. Именно исследование влияния двуосности молекул сегнетоэлектрических жидких кристаллов на параметры электрооптических эффектов может содействовать в получении поверхностей с заданными свойствами и управлению доменными структурами в электрооптических ячейках. В построенной модели мы учитываем деформацию поперечного сгиба спонтанной поляризации. Это означает, что можно рассчитать по величине электрического поля прикладываемое к ячейке напряжение и наоборот. В работе также изучено влияние коэффициента взаимодействия между директором и полимерной сеткой на распределение профиля директора 
вдоль ячейки. Установлено, что коэффициент взаимодействия между директором и полимерной сеткой даёт лишь незначительную разницу между профилями ориентации директора в фазе сегнетоэлектрического жидкого кристалла типа смектик $\mathrm{C}^{\star}\left(\mathrm{SmC}^{\star}\right)$. Мы полагаем, что данная теоретическая модель может быть полезна при изготовлении экспериментальных ячеек, так как вытекающие из двуосного поверхностного потенциала следствия открывают возможности получения би- и моностабильных ячеек поверхностно-стабилизированных сегнетоэлектрических жидких кристаллов, а также оценивать качество планарной ориентации директора.

Ключевые слова: тонкие плёнки, сегнетоэлектрические жидкие кристаллы, стабилизация полимером, уравнение Эйлера.

\section{Introduction}

Recent advances in applications of ferroelectric liquid crystalline materials are developing in two directions: synthesis of new materials [1] and tailoring the existing liquid crystalline materials by dispersing/doping dyes, nanoparticles $[2,3]$ and polymers $[4,5]$. The latter is the promising remedy to solve the inherent stability problems.

The addition of polymer network in ferroelectric liquid crystal (FLC) structure results in the interaction between the polymer and $\mathrm{SmC}^{\star}$ molecules, which adds new constraints on its dynamics [4]. As the result, stability of molecular alignment to mechanical stresses can be improved. In other words, the polymer network behaves as the template of the liquid crystal order in which it was formed, aiding to align the liquid crystal [5].

Pioneering theoretical studies, which suggested that smectic C phase of liquid crystals exhibits biaxiality were published in study [6]. Soon after this publication, the biaxiality was experimentally confirmed [7]. The reported values of optical biaxiality in FLCs range within 0.001 and $0.005[8,9]$. Such small values of biaxiality in $\mathrm{SmC}^{\star}$ phase can lead to difficulties for its direct optical applications. However, recently introduced biaxial surface potential allows adequate description of the hysteresis loop, qualitatively explains types of domain structures and methods for its control [10]. Experimental evidence of chevron structure transformation into quasi-bookshelf layer structure [11] have motivated us to elaborate the proposed model in terms of thermodynamically steady effects and the biaxial structure of FLCs.

In this study we employed the biaxial surface potential to analyze the interplay between the layer tilt angle and the molecular orientation angle at the surface. The treatment of this coupling enabled us to obtain the reasonable boundary conditions for the governing equation. With the aim to develop the model of polymer-stabilized (PS) FLC cell with commonly observed surface and volume effects, we extend theoretical results [12-14] for the ion-free case. Related to this, our model accounts smectic layer tilt and spatial inhomogeneities of the spontaneous polarization. The effects of polymer density on the alignment structure are also discussed. Consideration of these factors in PS FLC cell represents the novelty of our study.

\section{Electrostatic model}

Fig. 1 represents the illustration of $\mathrm{SmC}^{\star}$ layer, confined between the bounding surfaces, spaced by distance $d$. We denote the $y z$-plane parallel to the bounding surfaces, whilst the $x$-axis is perpendicular to the bounding surfaces. The most probable orientation of long molecular axes is characterized by the director $\mathbf{n}$. The unit orthogonal projection of $\mathbf{n}$ onto the smectic plane is conventionally described in terms of vector c (c-director). Due to the anchoring effects at the substrate, smectic layers are usually tilted from the surface normal by an $\delta$ angle [15], which is also the angle between the $z$-axis and the smectic layer normal $\mathbf{a}=(\sin \delta, 0, \cos \delta)$.

The uniaxially anisotropic boundary surface causes the director $\mathbf{n}$ preferably align along the rubbing direction, characterized by the unit vector $\mathbf{R}=(0,0,1)$. The $\mathrm{SmC}^{\star}$ molecules are confined to rotate within the smectic planes, while the director field is constrained to tilt away from the layer normal by angle $\theta$. Throughout this paper we will be referring to the director geometry introduced in ref. [16].

We can see immediately from Fig. 1 that $\varphi$ ranges within the interval $-\pi / 2 \leq \varphi \leq \pi / 2$, and we assume that it is also time-

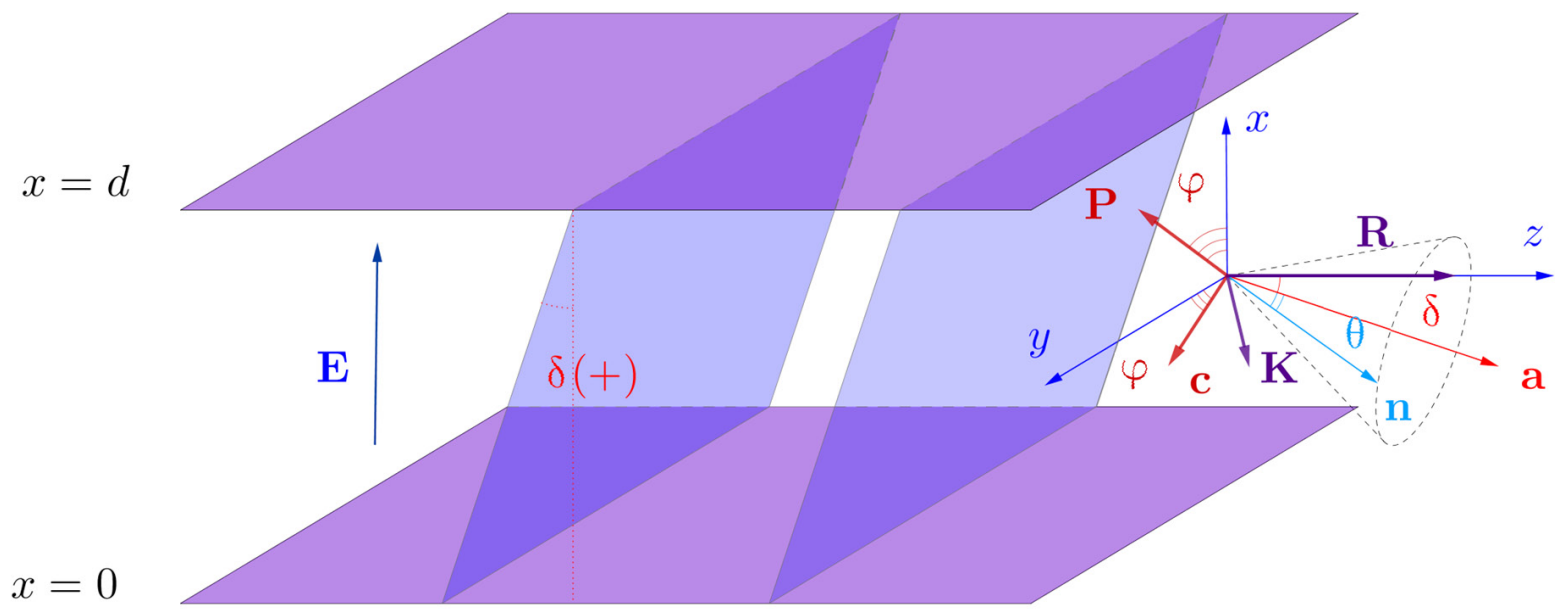

Fig. 1. Geometry of the FLC cell. The FLC director $\mathbf{n}$ lies on the smectic cone depicted by dashed lines with the smectic tilt angle $\theta$. Electric field $\mathbf{E}$ is applied across the cell. 
dependent, i. e., $\varphi=\varphi(x, t)$. It enables us to set the sign convention rule in such a way that the angles $\delta$ or $\varphi$ are considered negative or positive if measured in a clockwise or counterclockwise direction from the particular axis, respectively.

The bulk free energy density $f_{b}$ includes the elastic free energy density $f_{\text {elas }}$, contributions from the electric energy density $f_{\text {elec }}$ and the polymer network stabilization $f_{\text {stab }}$, i.e., $f_{b}=f_{\text {elas }}+f_{\text {elec }}+f_{\text {stab }}$. The total free energy of the PS FLC system is therefore given by

$$
F=\int_{0}^{d} f_{b} d x+\left.f_{s}(\varphi)\right|_{x=0}+\left.f_{s}(\varphi)\right|_{x=0}+\left.f_{s}(\varphi)\right|_{x=d},
$$

where $f_{s}(\varphi)$ represents interactions between the substrates and $\mathrm{SmC}^{\star}$ molecules.

A commonly used term to describe $f_{\text {elas }}$ in the oneconstant approximation is given by

$$
f_{\text {elas }}=\frac{B}{2}\left(\frac{\partial \varphi}{\partial x}\right)^{2}
$$

where $B$ is the elastic constant [17].

Assuming that the $P$-field is non-homogeneous along the $x$-axis, let $\mathbf{P}=P_{0} \mathbf{b}$, where $\mathbf{b}=[\mathbf{n} \times \mathbf{a}] /|\mathbf{n} \times \mathbf{a}|$ [19]. The splay of the $P$-field due to the electric field gives rise to polarization charge density $\rho=-\nabla \cdot \mathbf{P}$. After we apply the Gauss theorem, the polarization field is found to be

$$
E_{p}(x)=\frac{P_{0}}{\varepsilon} \cos \delta \cos \theta(1-\cos \varphi),
$$

where $\varepsilon$ is the absolute dielectric permittivity [17]. Consequently, the total electric field in the ion-free sample can be found as $E_{t o t}=E+E_{p}(x)$. Then the felec-term becomes

$$
f_{\text {elec }}=-\mathbf{P} \cdot \mathbf{E}_{\text {tot }} \text {. }
$$

As the argument to support the ion-free model, we refer to the experimental cell [18], which exhibits long-term bistability.

If the $\varphi$-dependence is known, the voltage $V$ across the FLC cell can be computed by the following relation

$$
V=E d+\frac{P_{0}}{\varepsilon} \cos \delta \sin \theta \int_{0}^{d}(1-\cos \varphi) d x
$$

Interaction between the polymer network and the FLC director can be regarded as a field-like effect, which is imposed to restore director to the preferred orientation. The well-known form of the $f_{\text {stab }}$-term reads as

$$
f_{\text {stab }}=\frac{\gamma_{s}}{2} \sin ^{2} \theta \sin ^{2}\left(\frac{\varphi-\varphi_{\text {stab }}}{2}\right),
$$

where $\gamma_{s}$ is the interaction coefficient between the director $\mathbf{n}$ and the polymer network, $\varphi_{\text {stab }}$ is the mean azimuthal angle of the polymer network field [4].

To set the boundary conditions, we use the biaxial surface potential [10]

$$
\begin{aligned}
f_{s}(\varphi)= & -\frac{w_{n}}{2}\left[(\sin \delta \cos \varphi \sin \theta+\cos \delta \cos \theta)^{2}+\right. \\
& \left.+\tilde{w}_{1} \sin ^{2} \varphi \cos ^{2}(\delta-\beta) \pm \tilde{w}_{2} \sin \varphi \cos (\delta-\beta)\right]
\end{aligned}
$$

where $\tilde{w}_{1}=w_{m} / w_{n}$ and $\tilde{w}_{2}=w_{p} / w_{n} \quad$ are the dimensionless anchoring energies; the $(-)$ sign applies to the bottom boundary, while the $(+)$ sign corresponds to the top boundary. The parameters $w_{n}, w_{m}, w_{p}$ have the following meanings: anchoring energy coefficient for the director with respect to the easy alignment axis R; anchoring energy coefficient, related to the inherent FLC biaxiality and the polar contribution associated with the presence of the polar axis, respectively.

It is clear that the surface treatment predetermines the layer tilt and the director orientation angles at the surfaces. So, we consider the torques $N_{\varphi}=-\partial f_{s} / \partial \varphi$ and $N_{\delta}=-\partial f_{s} / \partial \delta$. Equating $N_{\varphi}$ and $N_{\delta}$ to its maxima [13], we obtained the system of coupled equations. Substituting the typical model parameters (Table 1) into the system, it can be numerically solved. Recalling the range of feasible values for $\delta$ and $\varphi$, we can determine the layer tilt angle and the director orientation angle at the surface $\varphi_{s}$. The torque density fields $N_{\varphi}(\varphi)$ for a series of $\tilde{w}_{1}$ values and value pairs $\left(\delta, \pm \varphi_{s}\right)$ are given in Fig. 2 and its caption.

We can now write the time-dependent torque-balance equation in the form [20]

$$
\gamma_{\varphi} \frac{\partial \varphi}{\partial t}=\frac{d}{d x} \frac{\partial f_{b}}{\partial \varphi_{, x}}-\frac{\partial f_{b}}{\partial \varphi}
$$

The boundary conditions for equation (2) can be given as

$$
B \frac{\partial \varphi}{\partial x}-\left.\frac{\partial f_{s}}{\partial \varphi}\right|_{x=0}=0, \quad B \frac{\partial \varphi}{\partial x}+\left.\frac{\partial f_{s}}{\partial \varphi}\right|_{x=d}=0 .
$$

At this point it is convenient to introduce the quantities $\xi_{P}=\sqrt{\varepsilon B} / P_{0}, \quad \xi_{P E}=\sqrt{B \sin \theta \cos \delta} / P_{0} E, \quad \eta^{2}=\gamma_{s} \sin ^{2} \theta / 4 B$, $\tilde{\sigma}=\xi_{P}^{2} / \xi_{P E}^{2}$ and dimensionless variables $\tilde{x}=x / \xi_{P}, \tilde{t}=t / \tau$, where $\tau=\gamma_{\varphi} \cos \delta \sin \theta / P_{0} E$ is the characteristic time.

Table 1. Model parameters of the PS FLC cell.

\begin{tabular}{|c|c|}
\hline Tilt angle & $\theta=35^{\circ}$ \\
\hline Angle of polymer stabilization & $\varphi_{\text {stab }}=90^{\circ}$ \\
\hline Angle between the $x$-axis and vector $\mathbf{K}$ & $\beta=0$ \\
\hline Cell thickness & $d=1.6 \mu \mathrm{m}$ \\
\hline Spontaneous polarization & $P_{0}=75 \mathrm{nC} \cdot \mathrm{cm}^{-2}$ \\
\hline Electric constant & $\varepsilon_{0}=8.85 \cdot 10^{-12} \mathrm{~F} \cdot \mathrm{m}^{-1}$ \\
\hline Absolute dielectric permittivity & $\varepsilon=4 \varepsilon_{0}$ \\
\hline Elastic constant & $B=10^{-11} \mathrm{~N}$ \\
\hline Rotational viscosity & $\gamma_{\varphi}=50 \mathrm{mPa} \cdot \mathrm{s}$ \\
\hline Prime anchoring energy coefficient & $w_{n}=38 \cdot 10^{-3} \mathrm{~J} \cdot \mathrm{m}^{-2}$ \\
\hline Polar dimensionless anchoring energy & $\tilde{w}_{2}=0$ \\
\hline
\end{tabular}

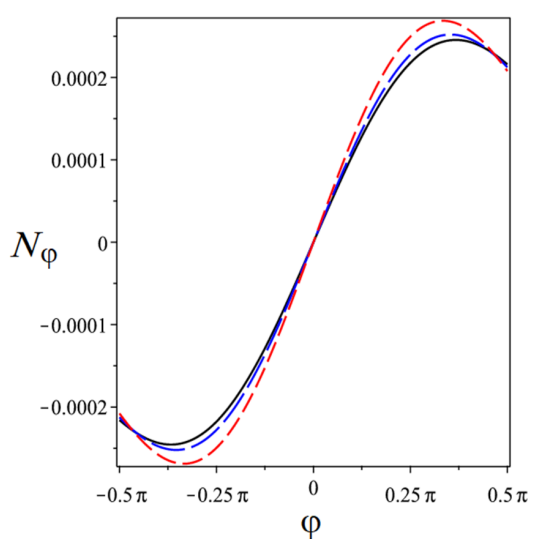

Fig. 2. Model surface torque density $N_{\varphi}\left[\mathrm{J} / \mathrm{m}^{2}\right]$ for different biaxial parameters: $\tilde{w}_{1}=0.4$ (solid curve), $\tilde{w}_{1}^{\varphi}=0.35$ (long-dashed curve) and $\tilde{w}_{1}=0.33$ (dashed curve). The calculated angles $\delta$ and $\varphi_{s}$ are $(-0.584, \pm 1.15) ;(-0.566, \pm 1.11)$ and $(-0.544, \pm 1.05)$, respectively. 


\section{Modelling}

The two calculated value pairs $\left(\delta, \pm \varphi_{s}\right)$ for each $\tilde{w}_{1}$ indicate two possible orientations of the director field, i.e., either preferably along or opposite the $x$-axis direction. Let $\tilde{w}_{1}=0.33$, then $\delta=-0.544 \mathrm{rad}, \varphi_{s}=-1.05 \mathrm{rad}$ (i.e., the electric field is applied along the positive $x$-axis direction). For the fixed director orientation angle at the surface, $\left(\delta, \pm \varphi_{s}\right)$ can be used to compute the torques applied to the surfaces.

If angle $\beta \neq 0$, then direct numerical computation of value pairs $\left(\delta, \pm \varphi_{s}\right)$ can represent a difficulty. However, by using the smallness of angle $\beta$, the multiplier $\cos ^{2}(\delta-\beta)$ of the biaxial surface potential can be approximated as follows: $\cos ^{2} \delta+\beta \sin (2 \delta)-\beta^{2} \cos (2 \delta)$. For the model parameters of Table 1 , but with $\beta=5^{\circ}$ we can easily obtain that $\delta=-0.53 \mathrm{rad}$, $\varphi_{s}= \pm 1.07 \mathrm{rad}$. Thus, the presence of the surface roughness plays a secondary role in the director orientation angle at the surface and the layer tilt angle.

Once the boundary conditions are specified, the model, represented by Eqs. (2) and (3) in terms of the normalized to the unit length variables can be handled with the material parameters of Table 1. Inspection of the model shows that for $\tilde{t} \gg 1$ its solution becomes stationary.

To calculate the applied voltage, we used the following approach: the cell width was divided into equally sized intervals with nodes $x_{i}$, where $i=1,2, \ldots, 20$. Consequently, the corresponding $\left(x_{i}, \varphi_{i}\right)^{i}$ pair values can be obtained. This set of points was interpolated by the Lagrange polynomial, and substituted into Eq. (1) in terms of the normalized to the unit length coordinates.

\section{Results and discussion}

The director orientation angle at the surface $\varphi_{s}$ will be driven further from its $0 \mathrm{~V}$ equilibrium position if the applied voltage increases. This gives rise to the formation of zones with length $\xi_{P E}$, which are attached to the surfaces and characterized by strong gradients in the $P$-field, exerting the conflict between electric and elastic torques via the boundary conditions. Elastic torque, applied by the electric field is the largest as $\varphi$ approaches to $\varphi_{s}$, and drops to zero when the $c$-director aligns perpendicular to the electric field and parallel to the $y z$-plane.

The director field configuration is twofold. First, the twist state near the bounding surfaces. Second, it is rather homogeneous over the bulk. When the absolute voltage increases (Fig. $3 \mathrm{a}$ ), the $c$-director tends to align perpendicular to the electric field, so the azimuthal angle profile asymptotically approaches zero. Consequently, the $f_{\text {stab }}$-term rapidly changes only within the zones with length $\xi_{P E}$. Once the applied voltages for several sampling electric fields are calculated, it enables us to depict the $(E, V)$ point values as shown in Fig. $3 \mathrm{~b}$. The interpolated curve represents a fairly linear $V(E)$-dependence.

If polymer stabilization energy density increases (Fig. 3c), the concavity of $c$-director orientation profile insignificantly decreases because the $f_{\text {stab }}$-term opposes the electric field density. As for the polymer-free FLC, the concavity of the $c$-director orientation profile insignificantly increases because the $f_{\text {stab }}$-term is considerably less than the $f_{\text {elec }}$-term. In other words, the amount of bulk polymer present in PS FLC system leads to the decrease of the dipole moment contribution. It means that the same light transmission will be obtained with higher voltages. At the same time, the presence of polymer network in the bulk makes the director orientation stable to the external influences.

The dipole field orientation organizes itself to increase the electric field due to the polarization charge in the regions of width $\xi_{p}-$ approximate thickness of the twist regions. The homogeneity degree strongly depends on the boundary conditions. This issue can be interpreted as the balance between the bulk anchoring strength of the polymer network and the surface anchoring strength.

A similar continuum model was developed in the earlier mentioned study [4]. Our discussion does not contradict the azimuthal angle distribution of this article, but rather supports a way to link complex geometry, anchoring effects and the alignment structure of ferroelectric liquid crystals with the model.

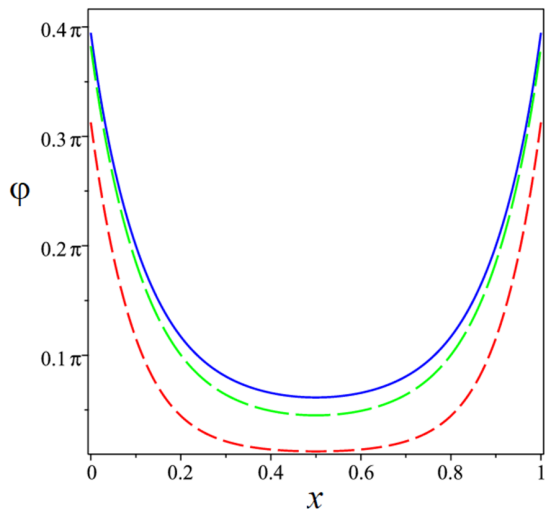

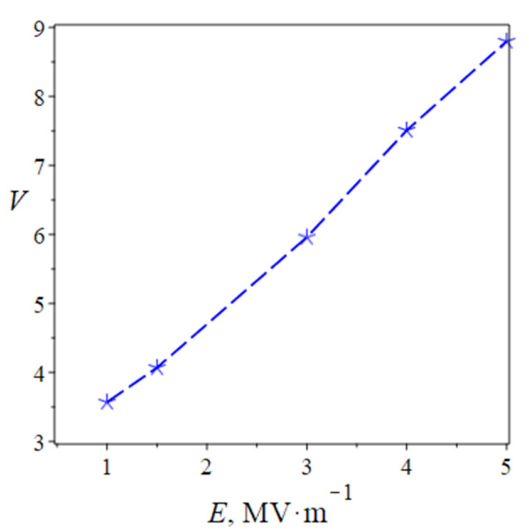

$\mathrm{b}$

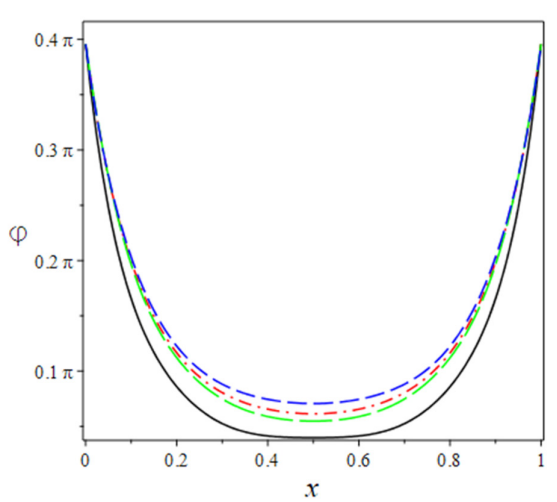

c

Fig. 3. Azimuthal angle profiles of the PS FLC cell. For varying electric fields: $E=1 \mathrm{MV} \cdot \mathrm{m}^{-1}$ (solid curve), $E=1.5 \mathrm{MV} \cdot \mathrm{m}^{-1}$ (long-dashed curve), $E=5 \mathrm{MV} \cdot \mathrm{m}^{-1}$ (dashed curve) at $\gamma_{\mathrm{s}} d=4.8 \cdot 10^{-4} \mathrm{~J} \cdot \mathrm{m}^{-2}$. The computed voltages: $3.57 \mathrm{~V}, 4.07 \mathrm{~V}, 8.8 \mathrm{~V}$, correspondingly (a). Applied voltage versus the electric field. Asterisks indicate the computed sampling points by Eq. (1), while the dashed curve is obtained by interpolation of the array point-values $(E, V)(\mathrm{b})$. For varying director-polymer network interaction coefficients at $E=1 \mathrm{MV} \cdot \mathrm{m}^{-1}$. The curves are computed for no polymer network interaction, i. e., $\gamma_{s}=0$ (solid curve), $\gamma_{s} d=1.6 \cdot 10^{-4} \mathrm{~J} \cdot \mathrm{m}^{-2}$ (long-dashed curve), $\gamma_{s} d=4.8 \cdot 10^{-4} \mathrm{~J} \cdot \mathrm{m}^{-2}$ (dash-dotted curve) $\gamma_{s} d=9.6 \cdot 10^{-4} \mathrm{~J} \cdot \mathrm{m}^{-2}$ (dashed curve). The computed voltages for the input parameters: $3.48 \mathrm{~V}, 3.57 \mathrm{~V}, 3.67 \mathrm{~V}, 3.81 \mathrm{~V}$ correspondingly (c). 


\section{Conclusions}

In this letter we have presented the influence of biaxial surface effects on the director orientation profile in PS FLC cell. The obtained boundary conditions allowed to elaborate the mathematical model of steady state effects in PS FLC cell. The computations we carried out suggest that the electrostatic energy can be low enough for surface forces to play an important role even when the director orientation profile is strongly stiffened within the $\xi_{P E}$-zones. Estimates of the total free energy do not exhibit its pronounced dependence versus the director-polymer network interaction coefficient due to the interplay between the bulk free energy density terms.

The quality of surface treatment can inhibit achieving the desired alignment uniformity. Consequently, the direction of vector $\mathbf{K}$ can be inclined by an angle $\beta$ with respect to the $x$-axis. Typical values of angle $\beta$ are about (or less than) $10^{\circ}$. Our estimations show that its presence in the $\tilde{w}_{1}$-term of the surface potential will not make significant change in angles $\delta$ and $\varphi_{s}$.

\section{References}

1. D. Weglowska, R. Dabrowski. Liq. Cryst. 41 (8), 1116 (2014). Crossref

2. R. K. Shukla, K. K. Raina, H. Wolfgang. Liq. Cryst. 41 (12), 1726 (2014). Crossref

3. S. Orlandi, E. Benini, I. Miglioli, D. R. Evans, V. Reshetnyak, C. Zannoni. Phys. Chem. Chem. Phys. 18 (4), 2428 (2016). Crossref

4. J. Li, X. Zhu, L. Xuan, X. Huang. Ferroelectrics. 277 (1), 85 (2002). Crossref

5. Y. Ma, L. Shi, A. K. Srivastava, V. G. Chigrinov, H. S. Kwok. Liq. Cryst. 43 (8), 1092 (2016). Crossref
6. A. Saupe. Mol. Cryst. Liquid Cryst. 7 (1), 59 (1969). $\underline{\text { Crossref }}$

7. T. R. Taylor, J. L. Fergason, S. L. Arora. Phys. Rev. Lett. 24 (8), 359 (1970). Crossref

8. J. K. Song, J. K. Vij, B. K. Sadashiva. J. Opt. Soc. Am. A. 25 (7), 1820 (2008). Crossref

9. J.K. Song, A.D. L. Chandani, A. Fukuda, J.K. Vij, I. Kobayashi, A. V. Emelyanenko. Phys. Rev. E. 76, 011709 (2007). Crossref

10. A. Kaznacheev, E. Pozhidaev, V. Rudyak, A. Emelyanenko, A. Khokhlov. Phys. Rev. E. 97, 042703 (2018). Crossref

11. H. Furue, Y. Iimura, H. Hasebe, H. Takatsu, S. Kobayashi. Mol. Cryst. and Liq. Cryst. Sci. and Tech. Sec. A. Molecular Crystals and Liq. Cryst. 317 (1), 259 (1998). Crossref

12. T. Takahashi, T. Umeda, H. Furue, S. Kobayashi. Jpn. J. Appl. Phys. 38, 5991 (1999). Crossref

13. M. J. O’Callaghan. Phys. Rev. E. 91, 022502 (2015). Crossref

14. A. A. Kudreyko, N. G. Migranov, D. N. Migranova. Chin. Phys. B. 25 (12), 126101 (2016). Crossref

15. T.P. Rieker, N.A. Clark, G.S. Smith, D.S. Parmar, E. B. Sirota, C. R. Safinya. Phys. Rev. Lett. 59 (23), 2658 (1987). Crossref

16. A. Meyere, P. Herman, E. de Ley. Liq. Cryst. 14 (5), 1269 (1993). Crossref

17. S. T. Lagerwall. Ferroelectric and Antiferroelectric Liquid Crystals. Weinheim, Wiley-VCH (1999) 319 p. Crossref

18. M. J. O'Callaghan, R. Ferguson, R. Vohra, W. Thurmes, A.W. Harant, C.S. Pecinovsky, M. A. Handschy. J.Soc. Info Disp. 17 (4), 369 (2009). Crossref

19. M. Nakagawa, M. Ishikawa, T. Akahane. Jpn. J. Appl. Phys. 27 (4), 456 (1988). $\underline{\text { Crossref }}$

20. I.-C. Khoo. Cholesteric, Smectic, and Ferroelectric Liquid Crystals. In Liquid Crystals. John Wiley \& Sons Inc. (2007) p. 92. $\underline{\text { Crossref }}$ 